$1-15-2019$

\title{
Application of Artificial Neural Networks to Assess Student Happiness
}

Gokhan Egilmez

Nadiye O. Erdil

Omid Mohammadi Arani

Mana Vahid

Follow this and additional works at: https://digitalcommons.newhaven.edu/ mechanicalengineering-facpubs

Part of the Industrial Engineering Commons, and the Mechanical Engineering Commons

\section{Comments}

This is the authors' accepted version of the article published in International Journal of Applied Decision Sciences. The version of record can be found at http://dx.doi.org/10.1504/IJADS.2019.098674 


\section{Application of Artificial Neural Networks to Assess Student Happiness}

${ }^{1}$ Gokhan Egilmez, ${ }^{2}$ Nadiye O. Erdil, ${ }^{3}$ Omid Mohammadi Arani, ${ }^{4}$ Mana Vahid

${ }^{1}$ Assistant Professor, Department of Mechanical and Industrial Engineering, University of New Haven, West Haven, CT, Email: Gegilmez@newhaven.edu Tel: (203) 479-4196

Address: 300 Boston Post Road, Buckman Hall 218, West Haven, CT 06516

${ }^{2}$ Assistant Professor, Department of Mechanical and Industrial Engineering, University of New Haven, West Haven, CT, Email: nerdil@newhaven.edu Tel: (203) 932-7251

Address: 300 Boston Post Road, Buckman Hall 223h, West Haven, CT 06516

${ }^{3}$ Graduate Student, Department of Mechanical and Industrial Engineering, University of New Haven, West Haven, CT, Email: omid.omo@gmail.com

Address: 300 Boston Post Road, Buckman Hall 225, West Haven, CT 06516

${ }^{4}$ Graduate Student, Department of Mechanical and Industrial Engineering, University of New Haven, West Haven, CT, Email: manavahid@gmail.com

Address: 300 Boston Post Road, Buckman Hall 225, West Haven, CT 06516

\section{Author Bios:}

Gokhan Egilmez, Ph.D.

Gokhan Egilmez is an Assistant Professor in the Department of Mechanical and Industrial Engineering at University of New Haven, West Haven, CT. He previously worked as assistant professor of Industrial and Manufacturing Engineering at North Dakota State University and postdoctoral research associate in the department of Civil, Environmental and Construction Engineering at University of Central Florida between 2013 and 2015. Gokhan obtained his Ph.D. in Mechanical and Systems Engineering and M.S. degrees in Industrial and Systems Engineering and Civil Engineering at Ohio University between 2007 and 2013. Prior to his education in the U.S., he went to Istanbul Technical University, Turkey and received B.S. in Industrial Engineering in 2007. His research interests cover a variety of topics that include applied optimization, simulation, sustainability, life cycle assessment, data analytics, engineering education, input-output analysis. For more information, please visit his personal blog at https://gokhanegilmez.wordpress.com

Nadiye O. Erdil, Ph.D.

Nadiye Özlem Erdil is an assistant professor of industrial and systems engineering at the University of New Haven. She has over twelve years of experience in higher education and has held several academic positions including administrative appointments. Prior to her academic career, Dr. Erdil worked as an engineer in sheet metal manufacturing and pipe fabrication industry for five years. She holds B.S. in Computer Engineering, M.S. in Industrial Engineering, and received her Ph.D. in Industrial and Systems Engineering from Binghamton 
University (SUNY). Her background and research are in quality and productivity improvement using statistical tools, lean methods and use of information technology in operations management. Her work is primarily in manufacturing and healthcare delivery operations.

Omid M. Arani

Omid M. Arani is a graduate of MS Industrial Engineering program at University of New Haven. He is currently working as Quality Engineer at Arizona Canning Company, LLC. He obtained his Bachelor's degree in Industrial Engineering from Azad University (IAU).

Mana Vahid

Mana Vahid is a graduate of MS Industrial Engineering program at University of New Haven. She is currently working as Data analyst at Edgewell Personal Care. She obtained her Bachelor's degree in Industrial Engineering Systems Analysis and Programming Azad University (IAU). 


\title{
Application of Artificial Neural Networks to Assess Student Happiness
}

\begin{abstract}
The purpose of this study is to develop an analytical assessment approach to identify the main factors that affect graduate students' happiness level. Two methods, Multiple Linear Regression (MLR) and Artificial Neural Networks (ANN), were employed for analytical modeling. A sample of 118 students at a small non-profit private university constituted the survey pool. Various factors including education, school facilities, health, social activities, and family were taken into consideration as a result of literature review in happiness assessment. A total of 32 inputs and 1 output variables were identified during survey design phase. Following survey conduction, data collection, cleaning, and preparation; MLR and ANNs were built. ANN models provided better classification performance with over 0.7 Rsquare and a smaller standard error of estimate compared to MLR. Major policy areas to improve student happiness levels were identified as career services, financial aid, parking and dining services.
\end{abstract}

Key words: student happiness, data analytics, neural networks, regression, higher education policy 


\section{Introduction}

Student satisfaction is among the key success factors in higher education quality and overall performance of educational institutions. Satisfaction is described as "fulfilment of one's wishes, expectations, or needs, or the pleasure derived from this"(Oxford University Press, 2018). The literature suggests that the student happiness is related to satisfaction (DeShields W. O. et al., 2005). Therefore, it is essential for an educational institution to provide a physical and social atmosphere to its students that foster happiness through satisfying their expectations as students. In order to provide such environment, it is necessary to identify the factors that affect happiness. Happiness is defined as an emotional state of feeling good (Layard, 2005). Since, people may have different understanding about happiness and their perception of happiness can differ, it is difficult to judge the level of happiness (Abecia et al., 2014). More importantly, it is noted that happiness is a feeling that is felt inwardly, which is hard to measure. However, the determinants of happiness could be further investigated. Assessed as an emotional state, happiness has been associated with various factors of professional and daily life in the literature. Some of the factors include wellness, spiritual stability, health status, friends and networks, along with individual growth (Abecia et al., 2014). Furthermore, productivity, salary, success, being energetic, sociable, having more fulfilling friendships are correlated with happiness in professional life (Martin, 2014). All in all, being in a happy state has substantial positive impacts on individuals' personal and professional lives. The literature is abundant with works which indicate that increased level of happiness leads to better physiological and physical perception of self, better dietary habits and maintenance of normal body weight, and physically active lifestyles (Stephanie \& M.Macleod, 2015); while unhappiness could make people perform poorly (Parkins et al., 2016).

The level of satisfaction, hence happiness, is an important factor for both individual and institutional success in higher education as well. The focus of this research is to investigate the determinants of happiness among university students with an integrated analytical approach. The integrated analytical framework is developed using a case study and is proposed to study the level of happiness. The framework consists of two phases. The first phase involves survey design and administration, and the second phase includes quantitative data analysis using regression and neural network models to examine the factors affecting student happiness. The rest of the paper is organized as follows. Section two explains recent studies in literature parallel to the focus of the current study. The methodology is explained in section three. Results are provided in section four. Finally, conclusions and future directions are provided in section five.

\section{Literature Review}

Happiness is a very broad topic that have been studied from various aspects and in various domains including work environment (Diener et al., 1993), society (Graham \& Felton, 2006), and particularly in higher education institutions (Abecia et al.,2014). As stated previously, satisfaction and happiness are positively correlated, and the terms are used interchangeably 
in the literature (Oxford University Press, 2018). Therefore, studies addressing happiness and satisfaction assessment in higher education context have been investigated in this section (Lu \& Argyle, 1994); (DeShields W. O. et al., 2005).

Studies on the linkage between student satisfaction and its positive effect on marketing of academic institutions show the importance of student satisfaction in higher education. Athiyaman (2001) indicates that student satisfaction leads to positive world-of-mouth communication, which in turn, influences prospective students' decision on university selection. Ismail et.al. (2011) argues that information about an institution is very important in attracting students which is highly depend on their satisfaction. Appleton-Knapp \& Krentler (2006) state that student satisfaction is a critical factor from marketing perspective. Their study shows that meeting student expectations has positive effect on student satisfaction. While the marketing aspect of student satisfaction is important for the survival of the academic institution, student satisfaction is also important in improving the educational quality of the institution. Student satisfaction highly effect their learning (Guolla, 1999) and there is a strong positive correlation between student satisfaction and exam results (Nyhus, 2015).

The marketing and educational quality outcomes are critical for academic institutions, thus, it is important to identify the predictors of student satisfaction. In one of the recent studies, Abecia et al. (2014) conducted a study measuring student happiness at the University of Mindanao, in which 381 students were surveyed on 34 pre-determined sources of happiness. Factor analysis was used as the quantitative assessment tool, which consisted of eight constructs including competition dimension, lifestyle dimension, intellectual, technology, altruism, night life, care dimension and celebrations. Results indicated that the top five indicators of happiness were family, health, academics, recognition and extending help to others. Furthermore, Howell \& Buck (2011) investigated various factors that could influence student satisfaction in a business college course. They categorized the factors on service aspects in three groups: institution driven, faculty driven, and student driven. They used multiple regression analysis to identify the relationship between the factors and student satisfaction. Results indicated that four out of eleven factors to be very influential. The factors were workload, relevancy of subject, faculty competency, and classroom management.

College experience is another factor that has been shown to impact student satisfaction. DeShields Jr. et al. (2005) studied 20 categories which may have an impact on students' college experience using Hertzberg's two-factor theory. The determinants of student satisfaction were categorized under three different groups: Faculty, advising staff, and classes. The faculty category included the following sub-categories: understandable, accessible, professional, helpful, and giving feedback. In advising staff understandable, accessible, responsive, helpful, and reliable sub-categories were grouped. It was concluded that classes and faculty have strong relation with students' college experience. Furthermore, the impact of college experience on student happiness was examined. Results showed that 
positive experience leads to student happiness which was correlated to higher student satisfaction.

Maceli et al. (2011) investigated gender and its impact on class experience from two different perspectives: whether the gender of the student is influential on satisfaction with class, and whether the gender of the instructor has impact on student satisfaction. They also considered other factors such as major, instructor age, and class rules. The result showed that not only the gender of the students is an indicator of student satisfaction from a course, but also is the gender of the instructor. They also found that instructor and classroom atmosphere to be important factors, and that clearly defined expectations and rules in their classes lead to student happiness. Shi et. al. (2014) also studied gender and age along with faculty and school in student satisfaction, and furthermore, examined the impact of other factors such as athletic facility, health center, and cafeteria on student satisfaction. School facilities such as library and laboratories are also identified to have critical impact on both student and staff satisfaction (Misanew \& Tadesse, 2014; Kärnä \& Julin, 2015).

On the other hand, some factors found to have negligible effect on student happiness. For instance, Gruber et al. (2010) stated that factors like attractiveness of the surrounding city, number of semesters, school placement, and atmosphere among students do not have impact on student satisfaction in higher education. Zarei (2013) indicates that parents' educational degree, religion, and student pocket money do not impact student happiness significantly. Abecia et al. (2014) pointed out that video games, nightlife, and barhopping minimally affect student happiness. But, it should be noted that the factors found to be negligible in general cases may become significant in a specific context. For instance; Hale et. al. (2009) discussed that student satisfaction factors in online courses are different from classroom courses. Student knowledge about technology in regular courses may not play an important role in their satisfaction but in the scope of online courses it has a high impact on their satisfaction (Burbuagh et al., 2014). The factors examined in another study were internet self-efficacy, self-directed learning, and online communication self-efficacy on student satisfaction, which were identified based on the study context: online programs (Kirmizi, 2015).

A large portion of the literature on finding the determinants of student satisfaction and happiness in various education levels heavily focus on student experience and teachers. Additionally, other factors that can potentially influence student satisfaction or happiness such as family-related issues, health-related issues, and social life could be of consideration. In this context, among handful studies that addressed such factors are as follows. Chen et. al., (2012) considered social and environmental factors to evaluate satisfaction in nursing students. In their study, social factors include faculty and student attitude toward each other and environmental factors refer to laboratories, classrooms, clinics, and similar schoolrelated facilities. Zarei, (2013) focused on religious, artistic, athletic experiences, and cultural factors. The results of their regression analysis study indicated that cultural and leisure activities were the top two factors that had critical impact on student happiness. Considering the all of the aforementioned works selected from the literature, two summary tables were prepared to group the indicators and research methods used. Table 1 
summarizes the most commonly addressed factors in student satisfaction and happiness studies. This information provides the basis of factor selection for our proposed measurement model. Table 2 shows the commonly used analysis approaches in these studies. Parametric methods including regression, factor analysis, $T$ test, have been the most popular methods, and university level assessment was the focus in the majority of the literature.

Table 1. Factors affecting Student Satisfaction

\begin{tabular}{|c|c|c|c|c|c|c|}
\hline Source & Education & Facilities & $\begin{array}{c}\text { Career and } \\
\text { financial aid } \\
\text { services }\end{array}$ & $\begin{array}{l}\text { Campus, dining } \\
\text { and healthcare }\end{array}$ & $\begin{array}{c}\text { Social } \\
\text { life }\end{array}$ & Family \\
\hline Guolla, (1999) & $\checkmark$ & & & & & \\
\hline Athiyaman (2001) & $\checkmark$ & $\checkmark$ & $\checkmark$ & & $\checkmark$ & \\
\hline Roszkowski and Ricci (2004) & $\checkmark$ & & & & & \\
\hline Naik and Ragothaman (2004) & $\checkmark$ & & & & & \\
\hline Oscar W. et al. (2005) & $\checkmark$ & & $\checkmark$ & & & \\
\hline Appleton-Knapp \& Krentler, (2006) & $\checkmark$ & & & & & \\
\hline Petruzzellis et. al., (2006) & $\checkmark$ & $\checkmark$ & $\checkmark$ & $\checkmark$ & $\checkmark$ & \\
\hline Hale at. el., (2009) & $\checkmark$ & & & & & \\
\hline Herzog (2009) & $\checkmark$ & & $\checkmark$ & & & \\
\hline Gruber et al. , (2010) & $\checkmark$ & $\checkmark$ & $\checkmark$ & $\checkmark$ & $\checkmark$ & \\
\hline Howell \& Buck (2011) & $\checkmark$ & & & & & \\
\hline Ismail et.al. , (2011) & $\checkmark$ & $\checkmark$ & $\checkmark$ & & & \\
\hline Maceli et al., (2011) & $\checkmark$ & & & & & \\
\hline Chen et.al., (2012) & $\checkmark$ & $\checkmark$ & & $\checkmark$ & & \\
\hline Zarei, (2013) & & & & $\checkmark$ & $\checkmark$ & $\checkmark$ \\
\hline Kardan et aL. (2013) & $\checkmark$ & & & & & \\
\hline Abecia et al. (2014) & $\checkmark$ & & & & $\checkmark$ & $\checkmark$ \\
\hline Misanew \& Tadesse, (2014) & & $\checkmark$ & & & & \\
\hline Shi et. al., (2014) & $\checkmark$ & $\checkmark$ & & $\checkmark$ & & \\
\hline Stukalina, (2014) & $\checkmark$ & $\checkmark$ & & $\checkmark$ & & \\
\hline Kärnä \& Julin, (2015) & & $\checkmark$ & & & & \\
\hline Kırmızı, (2015) & $\checkmark$ & & & & & \\
\hline Nyhus, (2015) & & $\checkmark$ & & & & \\
\hline Turkyilmaz et al. (2016) & $\checkmark$ & & $\checkmark$ & & $\checkmark$ & \\
\hline
\end{tabular}


Table 2. Overview of the recent literature

\begin{tabular}{lll}
\hline Source & Focus Area & Method(s) \\
\hline Guolla, (1999) & University & Partial Least Square \\
\hline Athiyaman (2001) & University & Regression \\
\hline Roszkowski and Ricci (2004) & University & Neural Networks \\
\hline Naik and Ragothaman (2004) & University & Neural Networks \\
Oscar W. et al. (2005) & University & Path Analysis \\
Appleton-Knapp \& Krentler, & & \\
(2006) & University & ANOVA, t test \\
\hline Petruzzellis et. al., (2006) & University & Chi Square Analysis \\
Hale at. el., (2009) & University & Chi Square, Fisher \\
\hline Herzog (2009) & University & Neural Networks \\
\hline Gruber et al. , (2010) & University & Regression \\
\hline & & T tests, Univariate Regression \\
Howell \& Buck (2011) & University & Analyses \\
\hline Ismail et.al. , (2011) & University & Factor Analysis \\
Maceli et al., (2011) & University & t tests, Regression \\
\hline Chen et.al., (2012) & University & Factor Analysis, ANOVA \\
Zarei, (2013) & University & t tests, Regression \\
\hline Kardan et aL. (2013) & University & Neural networks \\
\hline Abecia et al. (2014) & University & Exploratory Factor Analysis \\
Misanew \& Tadesse, (2014) & University & Factor Analysis, Regression \\
\hline Shi et. al., (2014) & University & ANOVA, Factorial Experiment \\
\hline Stukalina, (2014) & University & Regression \\
\hline Kärnä \& Julin, (2015) & University & Coefficient of Determination \\
Kırmizi, (2015) & University & Regression \\
\hline & Secondary & \\
Nyhus, (2015) & School & Regression \\
\hline Turkyilmaz et al. (2016) & University & Neural Networks \\
\hline
\end{tabular}

The information summarized in Tables 1 and 2 helped organizing the research methodology in alignment with the works done so far. Most commonly applied methods were parametric, which are typically expected to hold the assumptions of the data to be normal, homogeneous, and collected based on independent observations. Even though the third assumption could be automatically met if the surveys are independently conducted; the first and second assumptions may not be directly met when categorical and/or binary variables are generated after results of survey are converted into a quantitative dataset. Parametric methods (e.g. regression) typically formulate the relationship(s) between independent and dependent variables with linear functions. However, the causal or correlational relationships are not always linear and often more complex. In this regard, nonparametric methods are used as a robust approach to account for both linear and non-linear relationships; and provide statistically improved understanding about the relationships between the input and output variables(Brodsky \& Darkhovsky, 2000; Shokrzadeh et al., 2014). 
Among the nonlinear statistical modeling and analysis approaches, artificial neural networks has been used extensively in data mining, knowledge extraction, and statistical modeling applications that focus on a wide variety of areas including education, supply chain management (Ko et al., 2010), healthcare (Begg et al., 2006), buildings and construction (Tatari and Kucukvar, 2011), sustainability (Zhang, Shang, \& Wu, 2009), and transportation (Egilmez and McAvoy, 2017).

Related to the methodological focus of this study, neural networks; there are a few studies investigating not directly student happiness but related topics such as student success, retention rates, satisfaction, and loyalty. For instance, Herzog, (2009) focused on predicting retention and degree completion time and used neural networks to model the relationships between the second year retention rates (output) and various input variables including student demographics (age, gender, etc.), campus experience, financial aid, academic experience, etc. In another study, student achievement in online education systems (elearning) was investigated with neural network models (Roszkowski and Ricci, 2004). The study used multiple-choice tests' grades as the main dataset to have neural network models learn, and predict the student success. Results of the study indicated that prediction was possible at an early stage (the third week) of a 10 -week online course. Furthermore, Naik and Ragothaman (2004) focused on building neural network models to predict success of MBA students. Neural network models classified applicants into successful and marginal student categories with high and reliable accuracy. The variables used in the study included undergraduate GPA, GMAT scores, undergraduate major, age and other relevant data. Kardan et al. (2013) focused on students' course selection, where neural network models were used to understand the factors that affect the course selection in online environment. These studies successfully integrated neural networks into college education context, however student happiness were not directly addressed. In contrast, in a recent work, Turkyilmaz et al., (2016) focused on developing a composite satisfaction index for college students by using variables such as institutional image, student expectations, perceived quality, perceived value, student satisfaction, and student quality (Türkyılmaz \& Özkan, 2007). In this work, the composite index was developed as a result of survey factors and the sole focus was more on the university aspect. Student happiness, and determinants that are not directly related with the university were not considered.

Apart from the aforementioned works, to the best knowledge of authors, neural networks have not been used to model student happiness in the literature even though successful applications exist in similar problem domains, which were listed in Table 2. In addition to filling the gap in theoretical applications of neural networks to understand the determinants of overall student happiness; this study extends the topical focus by incorporating not only school-related factors; but also, the other factors such as family relationship and financial support, cultural and social activities to provide a more comprehensive and deeper understanding about the determinants of student happiness at higher education institutions.

\section{Methodology}


The methodology part consists four sections. In the first sub-section, study approach is summarized. Secondly, the survey design steps and details are provided. In the third subsection, the analytical assessment of survey results, which is performed with multiple linear regression (MLR) and artificial neural networks (ANN) models, are explained.

\subsection{Summary of the Approach}

The survey was designed with a project group, which consisted of two graduate students and a faculty mentor. After the approval of IRB, the survey was administered to the graduate student population at small non-profit private university across the college of engineering and other colleges. After the results were obtained and recorded, statistical and analytical assessments were performed. And, the study was concluded with sensitivity analysis.

\subsection{Survey Design}

Literature review, and brain storming and interview sessions with student and faculty groups were arranged to list the potential determinants of student happiness. Initially, seven main categories were identified: personal, education, facilities, career and financial aid services, campus dining and healthcare services, social life, and family (See Figure 1). Later on, main categories of student happiness determinants were extended to have subcategories prior to creating the questions. Various sub-categories such as classroom and technology, group working environment, financial aid, career center services, parking facilities, safety, food services, health center service, insurance, social activities, cultural events, and some personal factors like family relationship, financial support, etc. were identified (See Figure 1 for full list). Based on the main and sub-categories, 33 survey questions were prepared. Due to the difficulty in judging the level of happiness (Abecia et al., 2014), and that there is a positive correlation between student satisfaction and student happiness (DeShields W. O. et al., 2005), a five-point Likert scale with 5 indicating extremely satisfied and 1 indicating extremely dissatisfied was used for rating in each sub-category. For the final question which asks the participants to rate their overall happiness, a five point Likert scale with $5=$ extremely happy and $1=$ not happy was used. Then, 118 students representing a population of 1,800 were interviewed using paper-surveys and survey results were converted into a dataset to be used for analytical modeling. The response rate was 100 percent, and there were no missing values in responses. The expected margin of error for the survey was calculated as 8.8 percent with a 95 percent confidence level.

\subsection{Analytical Modeling: $M L R \& A N N$}

In the analytical modeling part, the results of surveys were analyzed visually, statistically, and analytically. While our primary goal was to develop artificial neural network (ANN) models, we also generated multiple linear regression (MLR) models. The MLR approach is commonly used in similar studies in literature. The purpose of using MLR models in this study was to establish a baseline for the ANN model. Data visualization techniques were initially used to extract initial interpretations and understanding about the relationships among the set of nominal and ordinal input and output variables. 

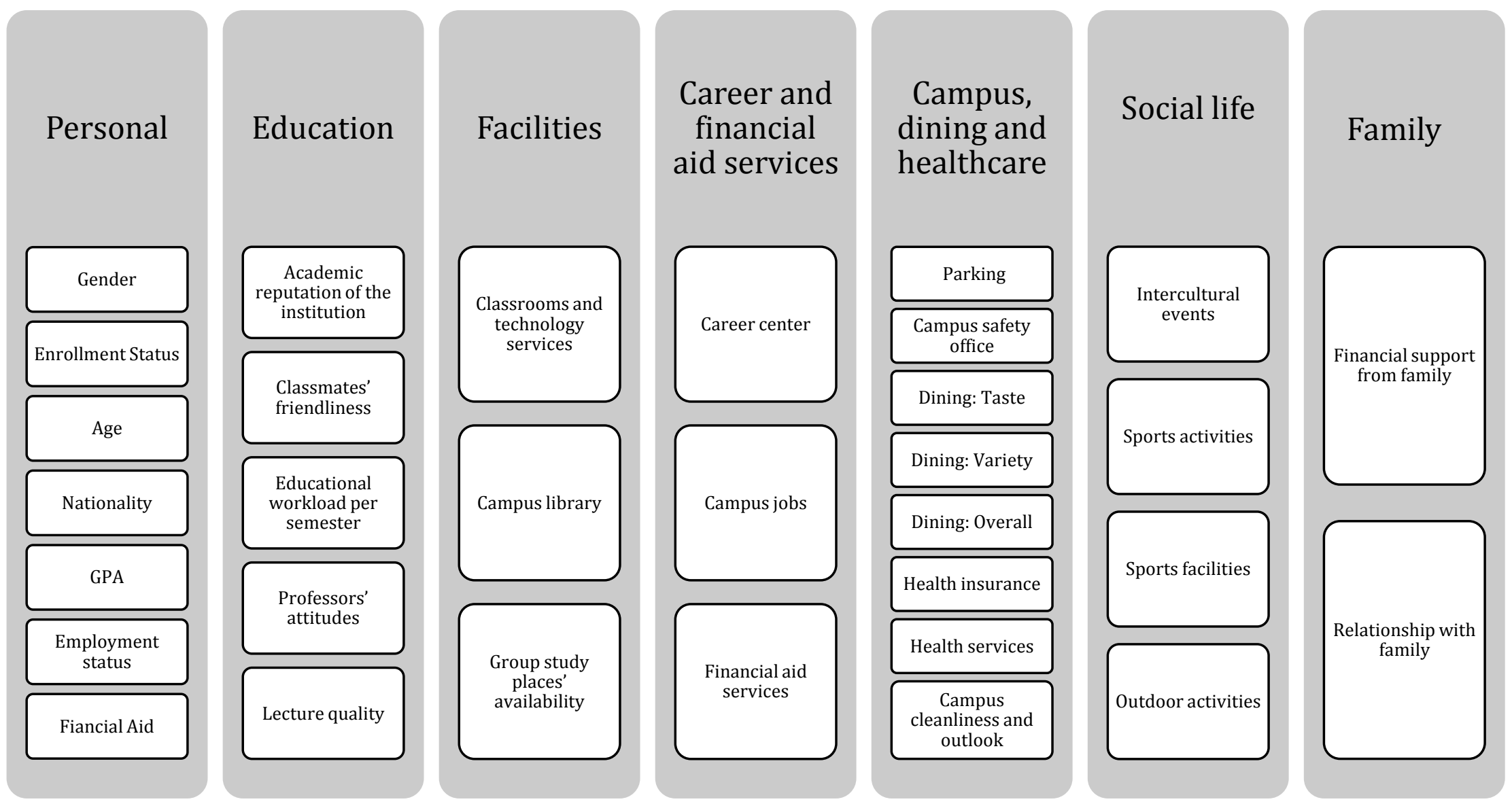

Figure 1. Input factors derived from literature 
After statistical analysis, to gain better and deeper understanding of the underlying relationships between the factors and the overall happiness, analytical models were developed. Initially, multiple linear regression (MLR) was utilized with stepwise and backward methods in SPSS software. Then, artificial neural network (ANN) models were built to predict student happiness and understand its critical determinants. In this context, backward MLR starts building models iteratively and removes statistically insignificant variables at each iteration until all the input variables are significant in the build model. In contrast, as a black-box modeling technique, ANN keeps all the variables and builds the neural network architecture while maintain all the variance information from all the input variables.

Multiple (Multivariate) Linear Regression (MLR) is typically used to model the relationship between a response variable and two or more explanatory variables. Following is a general form of MLR (Eq. 1).

$y=\beta+\sum_{i=1}^{n} c_{i} * x_{i}+\varepsilon$

An artificial neural network (ANN) is a specific application of artificial intelligence where the input and output relationships are modeled by using appropriate linear or nonlinear functions in a multi-layered network structure. ANN modeling mimics the way neurons communicate among each other. An ANN model typically consists of three components: 1) architecture 2) training or learning algorithm and 3) activation function(s). An illustration of a very simple neural network is provided in Figure 2, where $I_{i}$ represents the input neurons and $\mathrm{O}$ is the output neuron. $\mathrm{H}$ is a hidden layer, and $w_{i}$ represents the weight for the $i^{\text {th }}$ input.

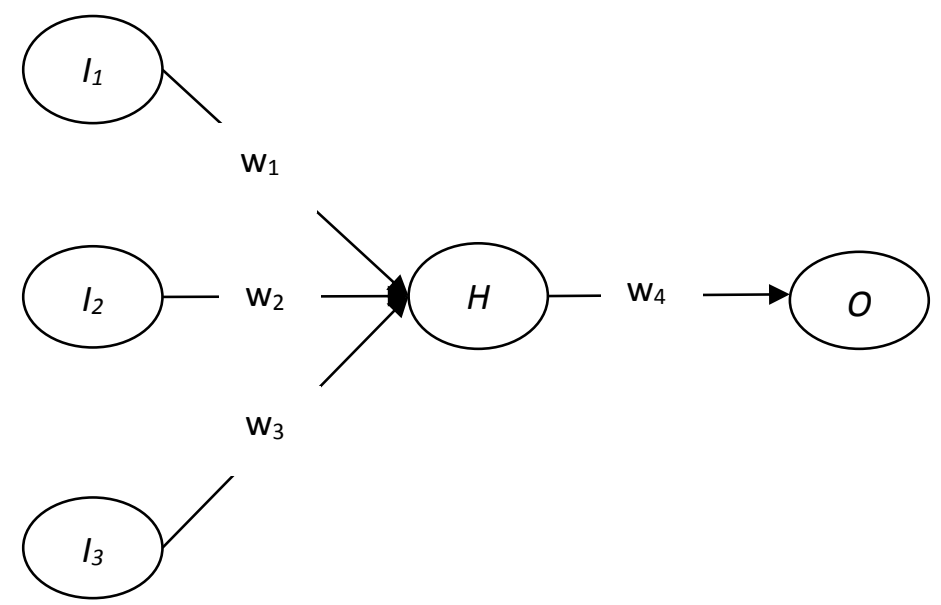

Figure 2. Simple ANN architecture (Egilmez and McAvoy, 2017)

In the neural network architecture shown in Figure 2, there are three inputs $\left(I_{1}, I_{2}, I_{3}\right)$, one output $(\mathrm{O})$ and one hidden unit $(\mathrm{H})$, where is a nonlinear activation function used to model the information process between inputs and output. Neural networks have been widely used in literature in various problem domains including forecasting (Sun \& Chang, 2016; Wang, 2016); financial efficiency assessment (Sun \& Chang, 2016), predictive modeling (Wang, 2016), quality management (Maleki et al., 2015); operational efficiency assessment 
(Mousavizadeh et al., 2017); consumer satisfaction assessment (Kar \& Singh, 2012), and education (Turkyilmaz et al., 2016).

\section{Results}

Results are described in four main sections. First, results are presented by each factor category. Then, the results of analytical assessment methods (MLR and ANN) are provided. In the third section, MLR and ANN methods are compared. The fourth section provides sensitivity analysis of the factor (determinants of happiness) with the overall happiness output variable.

\subsection{Overview by Major Category}

An overall analysis is conducted on the survey results to illustrate the results of happiness assessment by major category. Major categories include personal, education, facilities, career and financial aid services, campus, dining and healthcare, family and social life. The distribution of answers based on five-point Likert ratings in each sub-category and the response variable is listed in Table 3.

\subsubsection{Student demographics}

In this category, the following factors were included: gender, enrollment, age, nationality, GPA, employment and financial aid status. Figure 3 provides a graphical summary of distribution of answers in each sub-category. Results indicated that, two thirds of the students were male. Vast majority of the students were enrolled full time, international students, and with a GPA above 3.00. Almost two-thirds of the students were between 21 and 24 years of age. One-thirds of the students were working full time while about 10 percent were working part-time, the remaining were not employed. Majority of the students receive full or partial financial aid.

\subsubsection{Education}

The education-related questions were about the university's reputation, relationship with people, educational workload (e.g. homework project, etc.), instructors, and lectures. Summary of the responses is shown in Table 3. The weighted scores for education category were between 3.92 and 4.19 indicating that the students were fairly satisfied. 

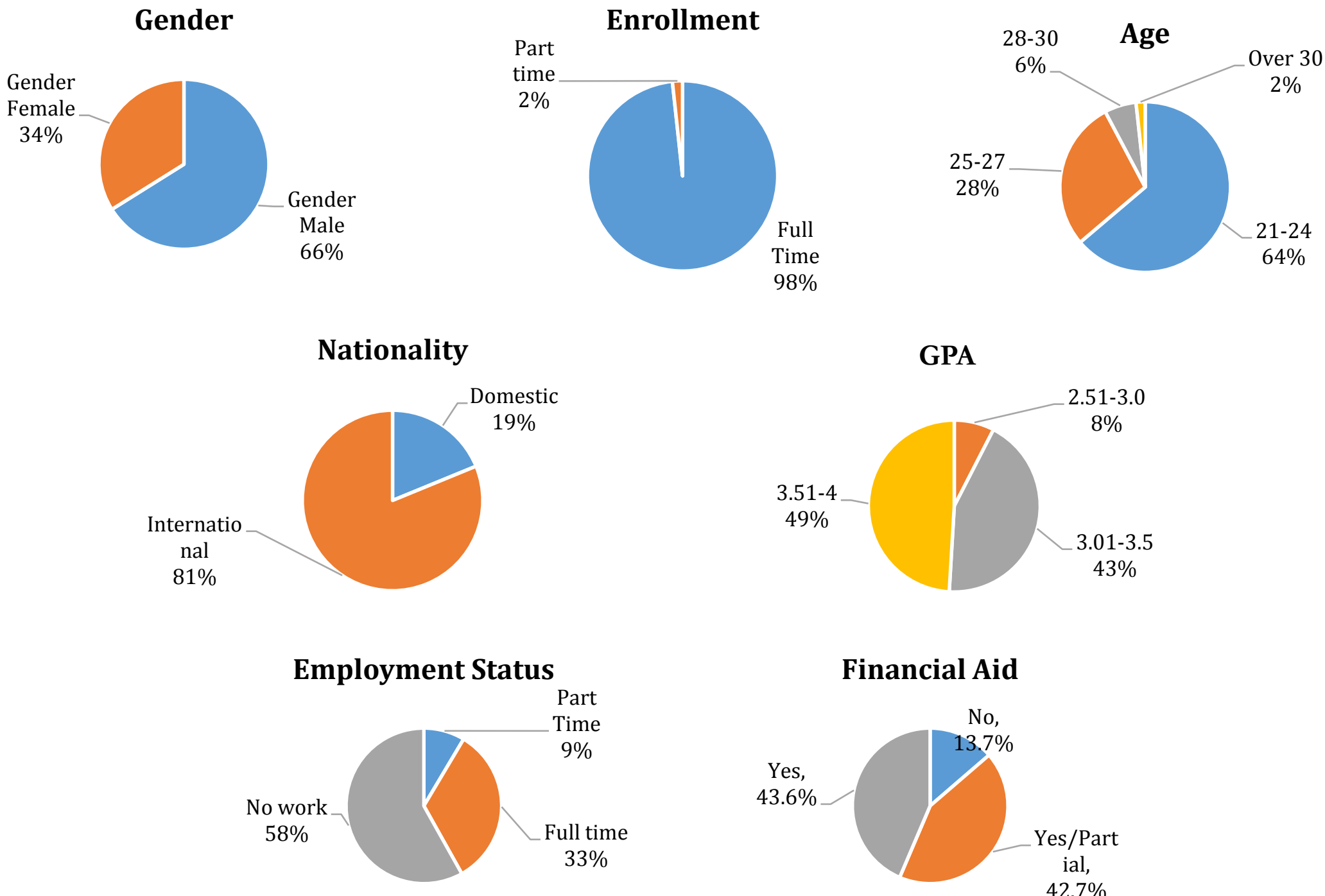

Financial Aid

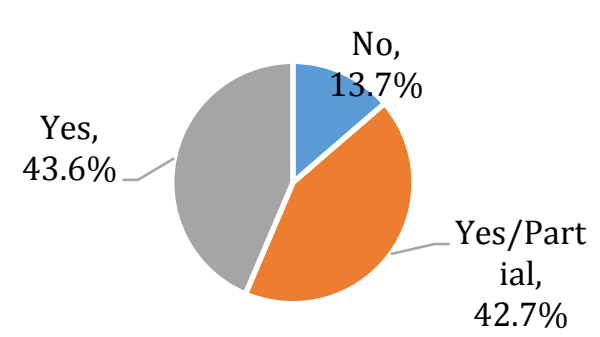

Figure 3. Student Demographics 
Table 3. Survey Results

\begin{tabular}{|c|c|c|c|c|c|c|c|}
\hline \multirow[t]{6}{*}{ Category } & $\begin{array}{l}\text { Please rate your level of } \\
\text { satisfaction in each of the following }\end{array}$ & 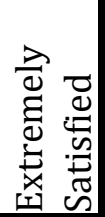 & 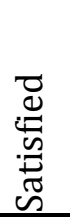 & 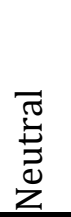 & 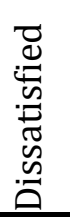 & 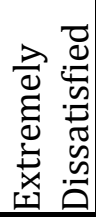 & 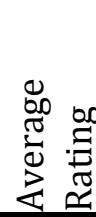 \\
\hline & $\begin{array}{l}\text { 1: Academic reputation of the } \\
\text { institution }\end{array}$ & 14 & 86 & 13 & 2 & 2 & 3.92 \\
\hline & 2: Classmates' friendliness & 42 & 65 & 5 & 4 & 2 & 4.19 \\
\hline & 3: Educational workload & 16 & 68 & 21 & 10 & 0 & 3.78 \\
\hline & 4: Instructors & 39 & 63 & 13 & 3 & 0 & 4.17 \\
\hline & 5: Lectures & 32 & 56 & 26 & 4 & 0 & 3.98 \\
\hline & $\begin{array}{l}\text { 6: Classrooms and technology } \\
\text { services }\end{array}$ & 30 & 56 & 22 & 10 & 0 & 3.90 \\
\hline & 7: Campus library & 46 & 49 & 13 & 9 & 1 & 4.10 \\
\hline & 8: Group study places & 21 & 58 & 26 & 10 & $\overline{3}$ & 3.71 \\
\hline & 9: Career center & 17 & 57 & 32 & 9 & 2 & 3.67 \\
\hline & 10: Campus jobs & 16 & 25 & 38 & 30 & 8 & 3.09 \\
\hline & 11: Financial aid services & 16 & 50 & 29 & 11 & 11 & 3.42 \\
\hline & 12: Parking & 10 & 29 & 29 & 23 & 27 & 2.76 \\
\hline & 13: Campus safety & 30 & 69 & 16 & 3 & 0 & 4.07 \\
\hline & 14: Dining services: Food taste & 16 & 44 & 40 & 13 & 5 & 3.45 \\
\hline & 15: Dining services: Food variety & 17 & 48 & 39 & 8 & 6 & 3.53 \\
\hline & $\begin{array}{l}\text { 16: Dining services: Overall } \\
\text { experience }\end{array}$ & 20 & 49 & 34 & 10 & 4 & 3.61 \\
\hline & 17: Health insurance & 13 & 64 & 35 & 1 & 4 & 3.69 \\
\hline & 18: Health services & 21 & 66 & 30 & 0 & 0 & 3.92 \\
\hline & $\begin{array}{l}\text { 19: Campus cleanliness and } \\
\text { outlook }\end{array}$ & 45 & 53 & 12 & 7 & 0 & 4.16 \\
\hline & 20: Intercultural events & 24 & 61 & 24 & 9 & 0 & 3.85 \\
\hline & 21: Sports activities & 13 & 62 & 34 & 7 & 1 & 3.68 \\
\hline & 22: Sports facilities & 24 & 64 & 19 & 10 & 1 & 3.85 \\
\hline & 23: Outdoor activities & 14 & 53 & 37 & 10 & 3 & 3.56 \\
\hline & 24: Financial support from family & 23 & 48 & 29 & 13 & 5 & $\overline{3.60}$ \\
\hline & 25: Relationship with your family & 87 & 23 & 6 & 0 & 1 & 4.67 \\
\hline
\end{tabular}




\begin{tabular}{|c|c|c|c|c|c|c|}
\hline & 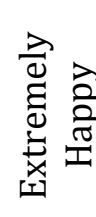 & $\begin{array}{l}\vec{a} \\
\frac{a}{0} \\
\frac{\pi}{1} \\
\overrightarrow{0} \\
\overrightarrow{0}\end{array}$ & 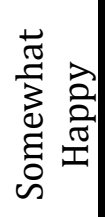 & 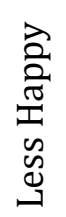 & 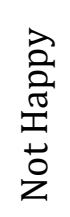 & \\
\hline $\begin{array}{l}\text { Overall } \\
\text { Happiness }\end{array}$ & 23 & 62 & 24 & 8 & 1 & 3.83 \\
\hline
\end{tabular}

\subsubsection{Facilities}

The facilities-related questions addressed classroom technology experience, library services, and available spaces to conduct group study. Similar to education-related factors, the weighted scores for facility-related factors were above 3.5.

\subsubsection{Career and financial aid services}

Although the factors related to career and financial aid services received lower weighted scores than the previous two categories, the results were still above 3.0, sufficient enough not to mark these factors as problem areas.

\subsubsection{Campus, dining, \& healthcare}

In this section, campus, dining, and healthcare-related questions were asked to the participants. The questions addressed parking, safety, dining, health insurance, health center and the general campus look. Results shown in Table 3 indicate that in all the categories students were satisfied except parking availability.

\subsubsection{Social life}

The topics of questions with respect to the social life category included quality of cultural events, variety of sports, sports facilities and outdoor activities. All of the weighted scores were higher than 3.5 indicating high student satisfaction for the social life category items.

\subsubsection{Family}

In this section, the family-related questions were asked to the participants. The two factors surveyed were the monetary support received from family (pocket money) and relationship with family. Results showed that the students were not only satisfied with family related matters, but also were extremely satisfied with their relationship with family as this factor received the highest score in the survey.

\subsubsection{Overall Analysis of Survey Results}

The distribution of answers in each sub-category and the response variable, overall happiness, are illustrated in Figure 4. For instance, in education area, there were five questions asked and approximately 58\% of the students gave a "satisfied" answer on average, and $24 \%$ said "extremely satisfied". Results indicate that the highest dissatisfaction levels were observed in career and financial aid services category. Especially, campus jobs, 
and career aid were selected as the main sources of dissatisfaction in this category. On the other hand, the highest level of satisfaction was achieved in the family section. Secondly, over $80 \%$ of the students were satisfied with the factors in the education category, and over $70 \%$ was satisfied with the facilities. Thirdly, among all sub-categories, parking was the only area that received more than $40 \%$ dissatisfaction. After parking, campus jobs was the secondary area with the highest dissatisfaction with over 30\%. Financial aid was found to be the third highest dissatisfaction source with almost $20 \%$. In terms of extremely satisfied and satisfied categories combined, sub-categories with the highest percent shares were found to be relationship with family (94\%), classmates (91\%), professor attitudes (86\%), university reputation (85\%), and campus safety (84\%).

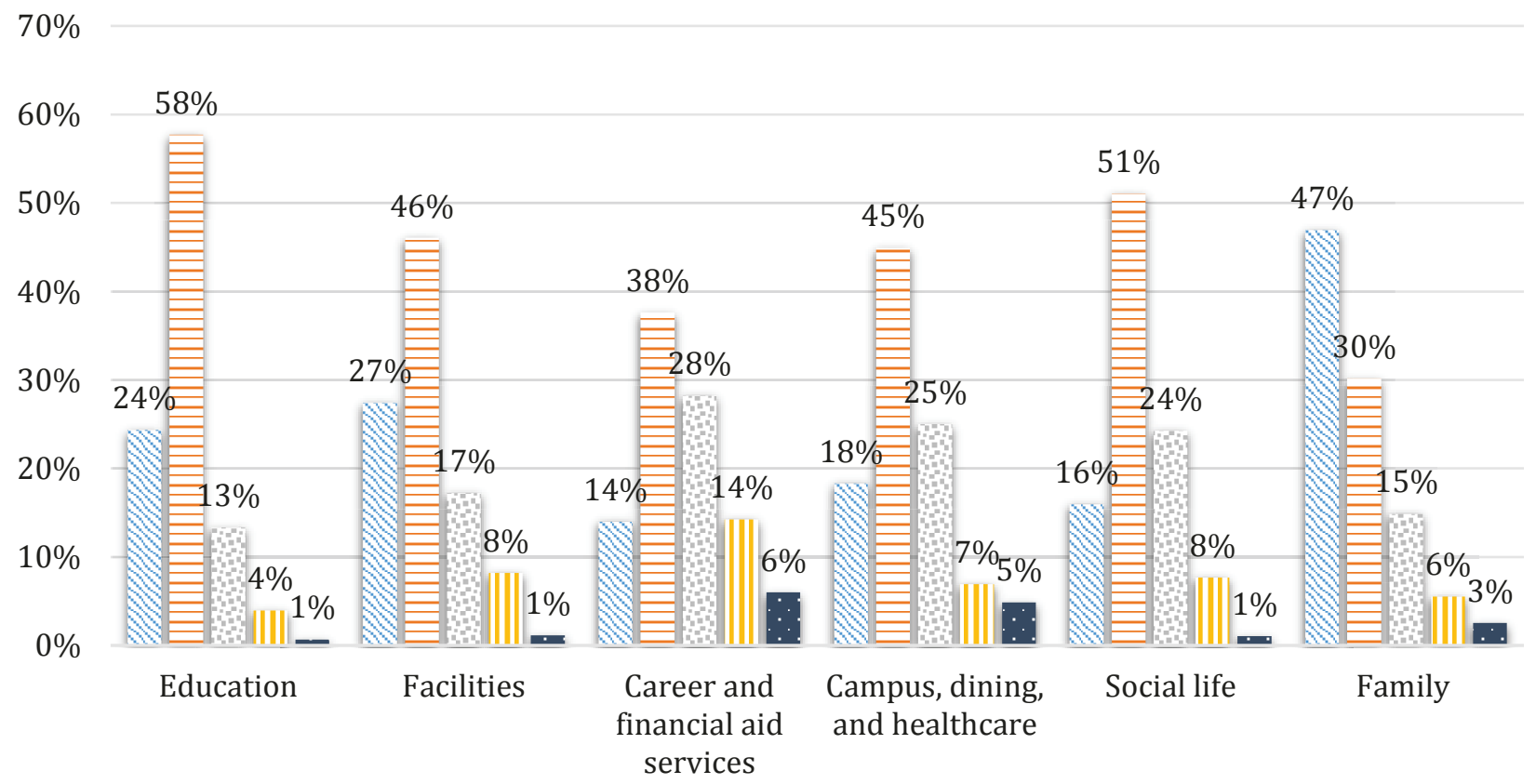

Extremely Satisfied = Satisfied Neither II Dissatisfied Extremely Dissatisfied

Figure 4. Average distribution of responses by Main Category

\subsection{The Analytical Approach: MLR and ANN models}

The analytical approach aims to quantify, thus helps to understand, the relationships between the categories that affect student happiness and the response variable (the level of overall happiness). The method selected for this study was ANN because ANN is a robust predictive and classification modeling technique that allows modeling both linear and nonlinear relationships between factor (input) and response (output) variables. However, two models were constructed: Multiple-Linear Regression (MLR) and Artificial Neural 
Networks (ANN) model. MLR is used as the benchmark method for ANN as previously used by similar studies including (Çodur \& Tortum, 2015; Egilmez \& McAvoy, 2017; Kaytez, Taplamacioglu, Cam, \& Hardalac, 2015; Şahin, Kaya, \& Uyar, 2013).

A total of thirty-two input variables and 1 response variable were used to model the relationship between the factors effecting happiness and the outcome (level of happiness). The response variable, the level of overall happiness, is a categorical variable, with categories Extremely Satisfied, Satisfied, Neither, Dissatisfied, Extremely Dissatisfied. The categorical values were converted into numbered categories between 1 and 5 with 1 being "not at all". Then models were constructed using SPSS and Statistica. The following sections provide results of both MLR and ANN models.

\subsubsection{Multiple Linear Regression (MLR)}

Twenty-eight multiple linear regression models were developed by using backward approach in SPSS. The model summary statistics are shown in Table 4. The best MLR model had an adjusted R-square of 0.477 and standard error of estimate (SEE) of 0.630 .

Table 4. Summary of Models Developed with Backward MLR

\begin{tabular}{|c|c|c|c|c|c|c|c|c|c|c|}
\hline \multirow[t]{2}{*}{ Model } & \multirow[t]{2}{*}{$\mathbf{R}$} & \multirow{2}{*}{$\begin{array}{c}\mathbf{R} \\
\text { Square }\end{array}$} & \multirow{2}{*}{$\begin{array}{l}\text { Adjusted } \\
\text { R Square }\end{array}$} & \multirow{2}{*}{$\begin{array}{c}\text { Std. } \\
\text { Error of } \\
\text { the } \\
\text { Estimate }\end{array}$} & \multicolumn{5}{|c|}{ Change Statistics } & \multirow{2}{*}{$\begin{array}{l}\text { Durbin- } \\
\text { Watson }\end{array}$} \\
\hline & & & & & $\begin{array}{c}\mathrm{R} \\
\text { Square } \\
\text { Change }\end{array}$ & $\begin{array}{c}\mathrm{F} \\
\text { Change }\end{array}$ & df1 & $\mathrm{df} 2$ & $\begin{array}{c}\text { Sig. F } \\
\text { Change }\end{array}$ & \\
\hline 1 & $.770^{\mathrm{a}}$ & .593 & .344 & .705 & .593 & 2.383 & 33 & 54 & .002 & \\
\hline 2 & $.770^{\mathrm{b}}$ & .593 & .356 & .698 & .000 & .000 & 1 & 54 & .987 & \\
\hline 3 & $.770^{c}$ & .593 & .367 & .692 & .000 & .016 & 1 & 55 & .901 & \\
\hline 4 & $.770^{\mathrm{d}}$ & .593 & .378 & .686 & .000 & .012 & 1 & 56 & .913 & \\
\hline 5 & $.770^{\mathrm{e}}$ & .593 & .389 & .680 & .000 & .024 & 1 & 57 & .876 & \\
\hline 6 & $.769^{f}$ & .592 & .398 & .675 & -.001 & .076 & 1 & 58 & .784 & \\
\hline 7 & $.769 \mathrm{~g}$ & .591 & .407 & .670 & -.001 & .183 & 1 & 59 & .671 & \\
\hline 8 & $.767^{\mathrm{h}}$ & .589 & .414 & .666 & -.002 & .251 & 1 & 60 & .618 & \\
\hline 9 & $.766^{\mathrm{i}}$ & .587 & .420 & .663 & -.002 & .315 & 1 & 61 & .576 & \\
\hline 10 & $.765^{j}$ & .585 & .427 & .659 & -.002 & .321 & 1 & 62 & .573 & \\
\hline 11 & $.764^{\mathrm{k}}$ & .583 & .434 & .655 & -.001 & .225 & 1 & 63 & .637 & \\
\hline 12 & $.762^{1}$ & .581 & .439 & .652 & -.002 & .352 & 1 & 64 & .555 & \\
\hline 13 & $.761^{\mathrm{m}}$ & .579 & .444 & .649 & -.002 & .381 & 1 & 65 & .539 & \\
\hline 14 & $.758^{\mathrm{n}}$ & .575 & .448 & .647 & -.004 & .628 & 1 & 66 & .431 & \\
\hline 15 & $.756^{\circ}$ & .571 & .451 & .645 & -.004 & .572 & 1 & 67 & .452 & \\
\hline 16 & $.754^{p}$ & .568 & .455 & .642 & -.003 & .478 & 1 & 68 & .492 & \\
\hline 17 & $.751^{q}$ & .565 & .459 & .640 & -.003 & .532 & 1 & 69 & .468 & \\
\hline 18 & $.749^{r}$ & .561 & .462 & .638 & -.004 & .604 & 1 & 70 & .440 & \\
\hline 19 & $.746^{\mathrm{s}}$ & .557 & .465 & .637 & -.004 & .584 & 1 & 71 & .447 & \\
\hline
\end{tabular}




\begin{tabular}{|lllllllllll|}
$\mathbf{2 0}$ & $.743^{\mathrm{t}}$ & .552 & .466 & .636 & -.005 & .887 & 1 & 72 & .349 & \\
$\mathbf{2 1}$ & $.740^{\mathrm{u}}$ & .547 & .468 & .635 & -.004 & .718 & 1 & 73 & .400 & \\
$\mathbf{2 2}$ & $.739^{\mathrm{v}}$ & .546 & .473 & .632 & -.001 & .235 & 1 & 74 & .630 & \\
$\mathbf{2 3}$ & $.735^{\mathrm{w}}$ & .540 & .473 & .632 & -.006 & .999 & 1 & 75 & .321 & \\
$\mathbf{2 4}$ & $.732^{\mathrm{x}}$ & .536 & .475 & .630 & -.004 & .710 & 1 & 76 & .402 & \\
$\mathbf{2 5}$ & $.729^{\mathrm{y}}$ & .531 & .477 & .630 & -.005 & .793 & $\mathbf{1}$ & $\mathbf{7 7}$ & .376 & \\
$\mathbf{2 6}$ & $.724^{\mathrm{z}}$ & .524 & .476 & .630 & -.006 & 1.075 & 1 & 78 & .303 & \\
$\mathbf{2 7}$ & $.717^{\text {aa }}$ & .514 & .472 & .632 & -.010 & 1.652 & 1 & 79 & .202 & \\
$\mathbf{2 8}$ & $.706^{\mathrm{ab}}$ & .498 & .461 & .639 & -.016 & 2.700 & 1 & 80 & .104 & 2.047 \\
\hline
\end{tabular}

MLR results indicated nationality $\left(x_{1}\right)$, career service $\left(x_{2}\right)$, campus safety $\left(x_{3}\right)$, sports $\left(x_{4}\right)$ and family relationship $(x 5)$, were the top five input variables effect student happiness. Results provided in Table 5 shows the details of the MLR model, including $r$, R and the standard error of estimate.

Following is the mathematical notation of the final MLR model.

$y=-1.24+0.38 x_{1}+0.24 x_{2}+0.24 x_{3}+0.41 x_{4}+0.21 x_{5}+\varepsilon$

where $\beta$ is the intercept term, $c_{i}$ (for $i=1 \ldots n$ ) are the regression coefficients, $\mathrm{y}$ is the response variable, $x_{i}$ (for $i=1 \ldots n$ ) are the independent predictor variables and $\varepsilon$ is the residual error.

Table 5. MLR Model Coefficients

\begin{tabular}{|c|c|c|c|c|c|c|c|c|c|c|c|c|}
\hline & \multicolumn{2}{|c|}{$\begin{array}{l}\text { Unstandardize } \\
\text { d Coefficients }\end{array}$} & \multirow{2}{*}{$\begin{array}{c}\begin{array}{c}\text { Standa } \\
\text { rdized } \\
\text { Coeffici } \\
\text { ents }\end{array} \\
\text { Beta }\end{array}$} & \multirow[t]{2}{*}{$\mathbf{t}$} & \multirow[t]{2}{*}{ Sig. } & \multicolumn{2}{|c|}{$\begin{array}{c}95.0 \% \\
\text { Confidence } \\
\text { Interval for B }\end{array}$} & \multicolumn{3}{|c|}{ Correlations } & \multicolumn{2}{|c|}{$\begin{array}{l}\text { Collinearity } \\
\text { Statistics }\end{array}$} \\
\hline & B & Std. Error & & & & $\begin{array}{l}\text { Lower } \\
\text { Bound }\end{array}$ & $\begin{array}{l}\text { Upper } \\
\text { Bound }\end{array}$ & $\begin{array}{l}\text { Zero- } \\
\text { order }\end{array}$ & Partial & Part & Tolerance & VIF \\
\hline (Constant) & -1.24 & .74 & & -1.68 & .09 & -2.72 & .23 & & & & & \\
\hline -Gender & .23 & .15 & .12 & 1.54 & .12 & -.06 & .54 & .24 & .17 & .12 & .89 & 1.11 \\
\hline -Nationality & .38 & .18 & .18 & 2.06 & .04 & .01 & .76 & -.07 & .22 & .16 & .72 & 1.38 \\
\hline -GPA & -.11 & .11 & -.08 & -1.03 & .30 & -.34 & .10 & -.04 & -.11 & -.08 & .85 & 1.17 \\
\hline $\begin{array}{l}\text {-Career } \\
\text { Services }\end{array}$ & .24 & .09 & .25 & 2.49 & .01 & .050 & .44 & .50 & .27 & .19 & .57 & 1.72 \\
\hline $\begin{array}{l}\text {-Campus } \\
\text { Safety }\end{array}$ & .24 & .11 & .19 & 2.15 & .03 & .019 & .48 & .37 & .23 & .16 & .70 & 1.41 \\
\hline $\begin{array}{l}\text {-Campus } \\
\text { Cleanliness }\end{array}$ & .13 & .09 & .13 & 1.41 & .16 & -.05 & .32 & .42 & .15 & .10 & .66 & 1.49 \\
\hline -Sports & .41 & .09 & .36 & 4.18 & .00 & .21 & .60 & .52 & .42 & .32 & .79 & 1.25 \\
\hline $\begin{array}{l}\text {-Pocket } \\
\text { Money }\end{array}$ & .08 & .08 & .10 & 1.04 & .30 & -.08 & .26 & .34 & .11 & .08 & .62 & 1.58 \\
\hline $\begin{array}{l}\text {-Family } \\
\text { Relationship }\end{array}$ & .21 & .11 & .18 & 1.92 & .05 & -.00 & .44 & .14 & .21 & .15 & .67 & 1.48 \\
\hline
\end{tabular}




\subsubsection{Artificial Neural Networks (ANN)}

In this study, thirty-two input variables and the student happiness, as the output variable, were used to build the ANN model. Seventy percent of the data was used for training and the remaining thirty percent was equally divided between validation (15 percent) and test (15 percent) data as commonly performed in the literature (Tatari and Kucukvar, 2011). The ANN model randomly selected data and assigned them to use for testing, validation and training. To train the networks developed and identify the weights and activation functions on the neural network nodes, training data was used. Validation step was to help minimizing the over-fitting; finally, 15 percent of data randomly selected to test to confirm the predictive power of the network. STATISTICA $®$ software was used for ANN modeling and analysis. Five activation functions (logistic sigmoid, hyperbolic, tangent, negative exponential and identity) were used to model linear and nonlinear relationships between the variables and the output. Automated Neural Network search was conducted and a total of 1000 networks were trained, validated, and tested. The results of the automated ANN experiment are provided in Table 6, where the top 5 networks are provided with their performance metrics. The ANN architecture is given in Figure 5.

Table 6. Results of Automated ANN Experiment (Top 5 Neural Networks)

\begin{tabular}{lccccc}
\hline Parameter & ANN-1 & ANN-2 (Best) & ANN-3 & ANN-4 & ANN-5 \\
\hline Network name & MLP 149-12-1 & MLP 149-8-1 & MLP 149-16-1 & MLP 149-8-1 & MLP 149-13-1 \\
Training R-square & 0.98 & 0.97 & 0.96 & 0.97 & 0.95 \\
Test R-square & 0.52 & 0.70 & 0.49 & 0.65 & 0.64 \\
Validation R-square & 0.53 & 0.47 & 0.52 & 0.46 & 0.43 \\
Training SEE & 0.01 & 0.01 & 0.02 & 0.019 & 0.03 \\
Test SEE & 0.37 & 0.26 & 0.40 & 0.29 & 0.29 \\
Validation SEE & 0.39 & 0.39 & 0.37 & 0.41 & 0.505 \\
Training algorithm & BFGS 13 & BFGS 12 & BFGS 12 & BFGS 12 & BFGS 9 \\
Error function & SOS & SOS & SOS & SOS & SOS \\
Hidden activation & Exponential & Exponential & Exponential & Exponential & Identity \\
Output activation & Logistic & Logistic & Logistic & Logistic & Sine \\
\hline
\end{tabular}


1. Gender

2. Age

3. Nationality

4. GPA

5. Financial aid

31. Family support

32. Family Relationship

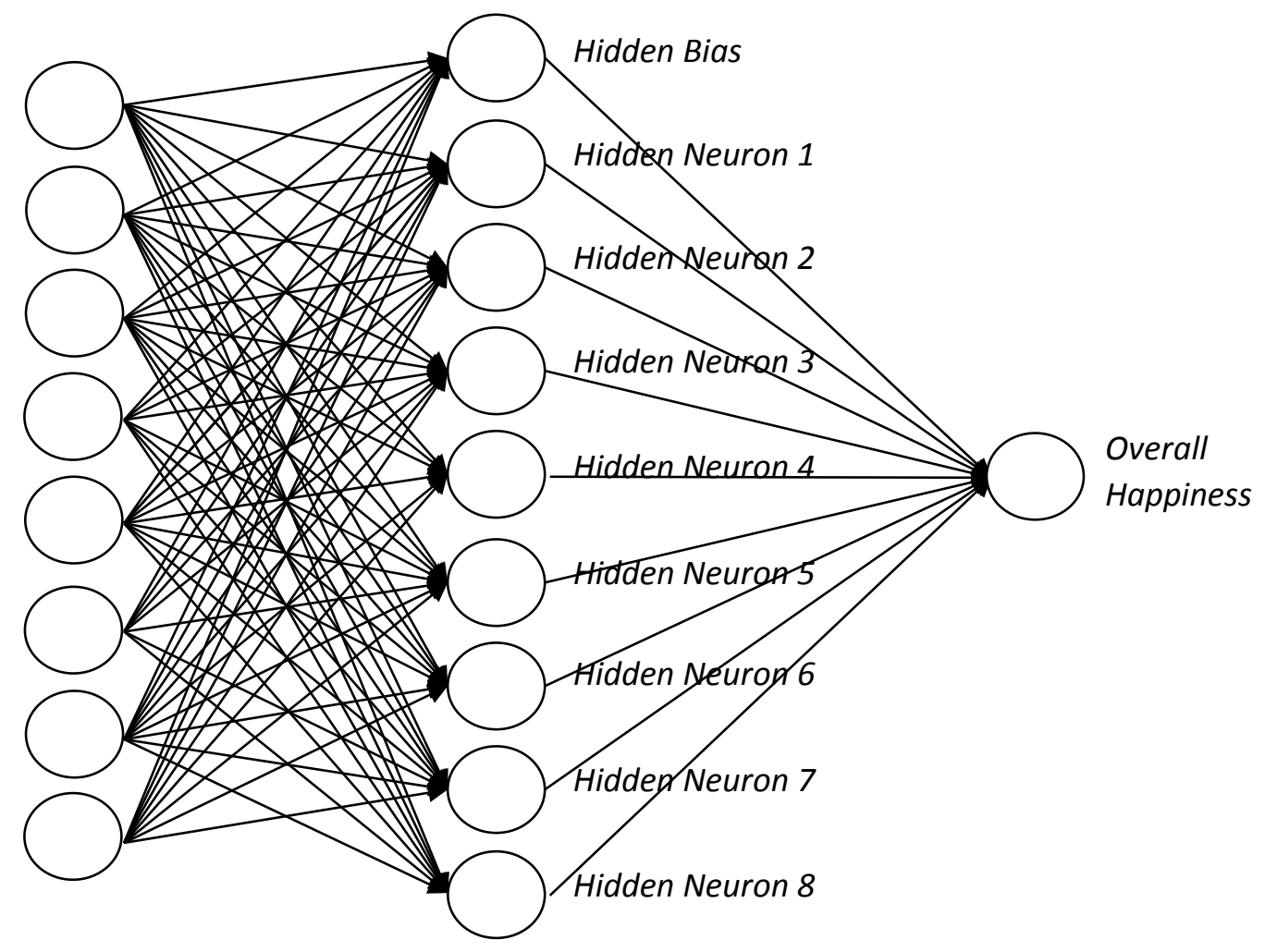

Figure 5. Architecture of the best ANN network (ANN-2)

Automated ANN experimentation resulted in five candidate ANN models. While all models have high training R-square, the second model has the least standard error estimate (SEE) and highest test R-square. Models with test R-square values that are greater than 0.7 generally indicate quite powerful classification and prediction performance (Tatari and Kucukvar 2011). Therefore, ANN Model-2 is selected for further analysis. The ANN Model-2, shown in Figure 5, consists of 32 input neurons, 8 hidden neurons in a single hidden layer and one output neuron (the level of happiness).

Figure 6 shows the classification performance of the best ANN model. The actual data are represented on the $x$-axis, whereas predicted (model's output) data are plotted on $y$-axis. According to Figure 6, majority of the data points $(x, y)$, were scattered around the diagonal line which indicates high classification power. The standardized residual graph is given in Figure 7. In a typical standardized residual graph, a good model's residuals typically tend to range around the horizontal 0 line, the more points close to zero line indicates less classification or prediction error. The graph in Figure 7 indicates that majority of the residuals were stacked around the 0 horizontal line, which indicates also a sound classification performance. 


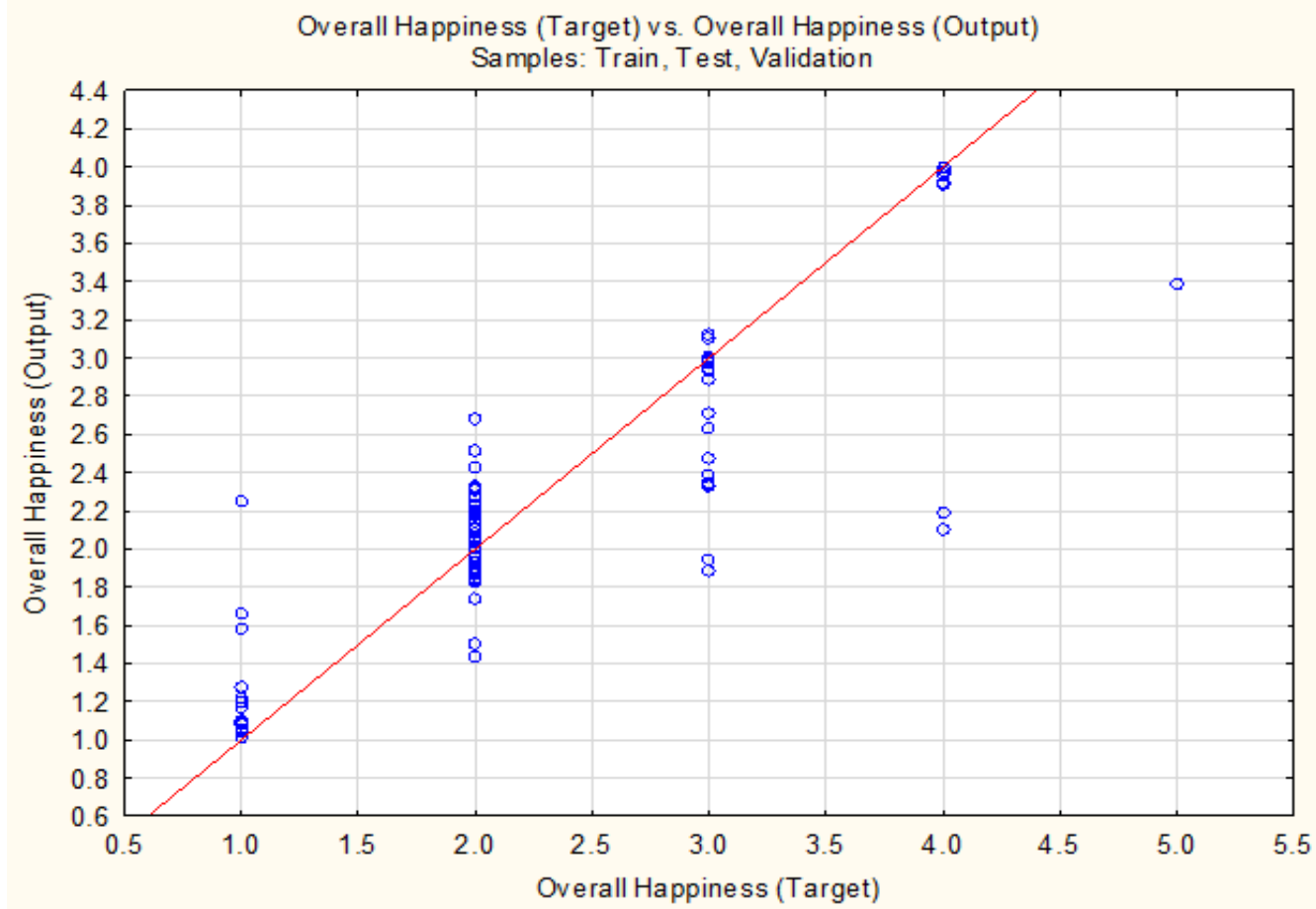

Figure 6. ANN's Classification Performance (Target vs. Output)

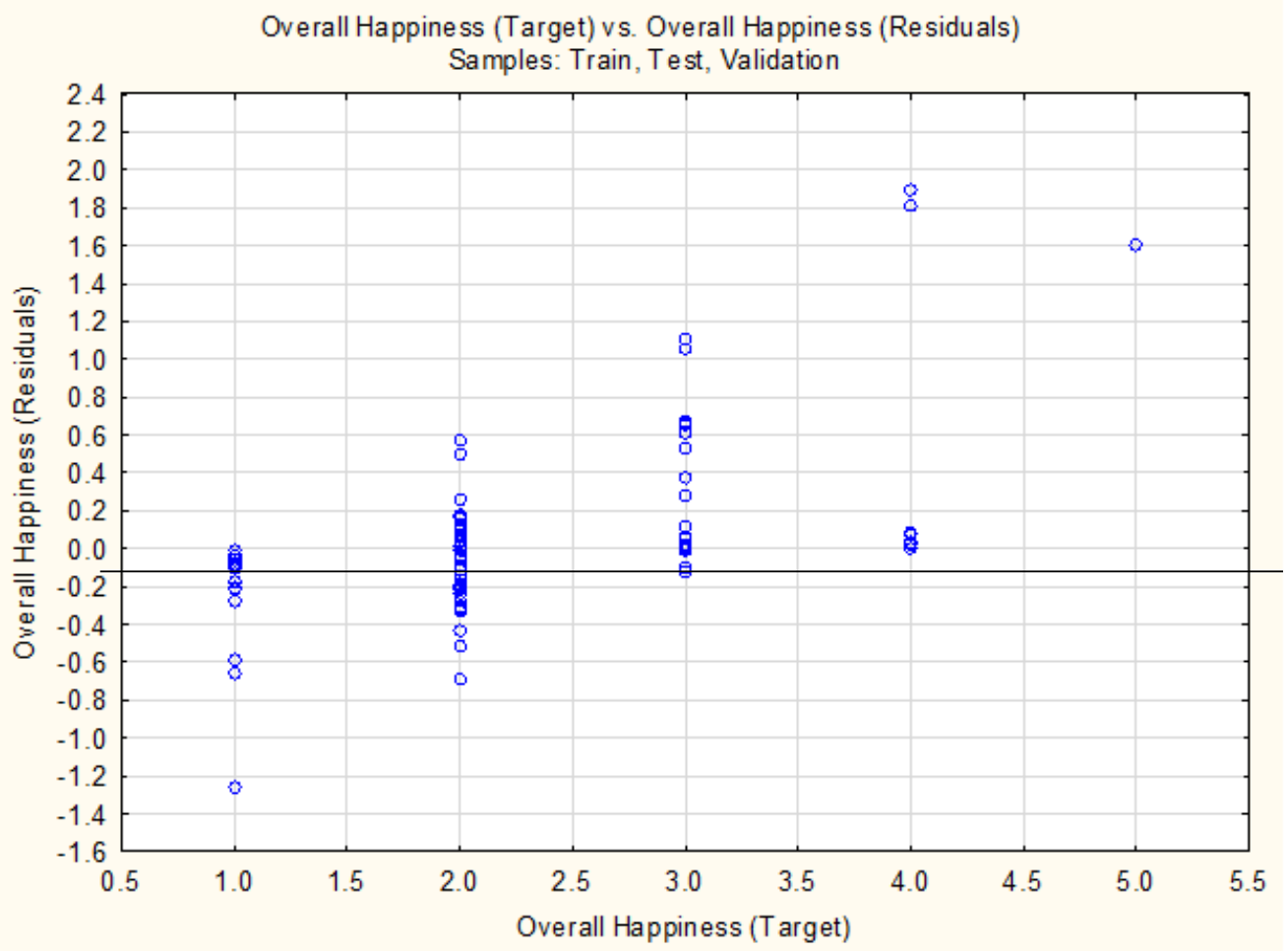

Figure 7. Residual Plot of ANN Model 


\subsection{Benchmarking ANN with MLR}

This section compares the performance of the proposed ANN model with MLR. In statistics, the coefficient of determination $\left(\mathrm{R}^{2}\right)$ and the standard error of estimate (SEE) are two important factors which indicate the strength of the models and are used for model comparisons (Tatari and Kucukvar, 2011). $\mathrm{R}^{2}$ provides a quantitative understanding about of the proportion of variability in the output explained by the inputs as a result of a statistical model. Standard error of estimate (SEE) is used to evaluate the accuracy of the model and quantifies the deviation of the predicted values from the actual values.

Table 7 shows $\mathrm{R}^{2}$ and SEE statistics for ANN and MLR models. As the data suggests, ANN model provides a stronger model with $\mathrm{R}^{2}$ of 0.70 ; which shows that nearly $71 \%$ of the variation is being explained with the ANN model. ANN model also was found to have significantly lower SEE (97.5\% less than MLR), which is an indicator of a more reliable model.

Table 7. Comparison of ANN and MLR

\begin{tabular}{lcc}
\hline & ANN (The Best Model) & MLR (The best model) \\
\hline $\mathbf{R}^{\mathbf{2}}$ & 0.707 & 0.531 \\
SEE & 0.016 & 0.630 \\
\hline
\end{tabular}

\subsection{Sensitivity Analysis}

Global sensitivity analyses provide quantitative understanding about the relative importance of the variables used in a neural network. The relative importance is assessed through submitting the dataset (test data) to the network repeatedly, while each variable is replaced with its mean value (calculated from training sample), and the resulting network error is recorded (Statistica, 2017). The global sensitivity analysis approach is based on missing value substitution procedure. In this procedure, each input variable is taken out of the neural network architecture to identify the relative contribution that is obtained by comparing the cases before and after exclusion of the variable (Egilmez et al., 2016). The test sample is used to calculate the sensitivity of an input variable; thus, the network error is determined. Moreover, the observed values of variable are replaced with the values estimated by the missing value procedure and the network error is calculated again. Then, the sensitivity is determined by calculating the ratio of the error with missing value substitution to the original error (Statistica, 2017). Sensitivity analysis for the ANN model constructed for this study indicates the degree of importance of input variables (factors) which are identified based on their influence on the student happiness, the output. The tornado diagram shown in Figure 8 presents the ranges of sensitivity scores for each main category. The average sensitivity scores of all factors (sub-categories) are presented in Table 8. The top three most sensitive sub-categories were found to be Nationality (1.36), Career center (1.29), and Sports activities (1.25), and the least three sensitive sub-categories were 
found to be Places for group working (1), Overall dining services (1), and Educational workload (0.99)

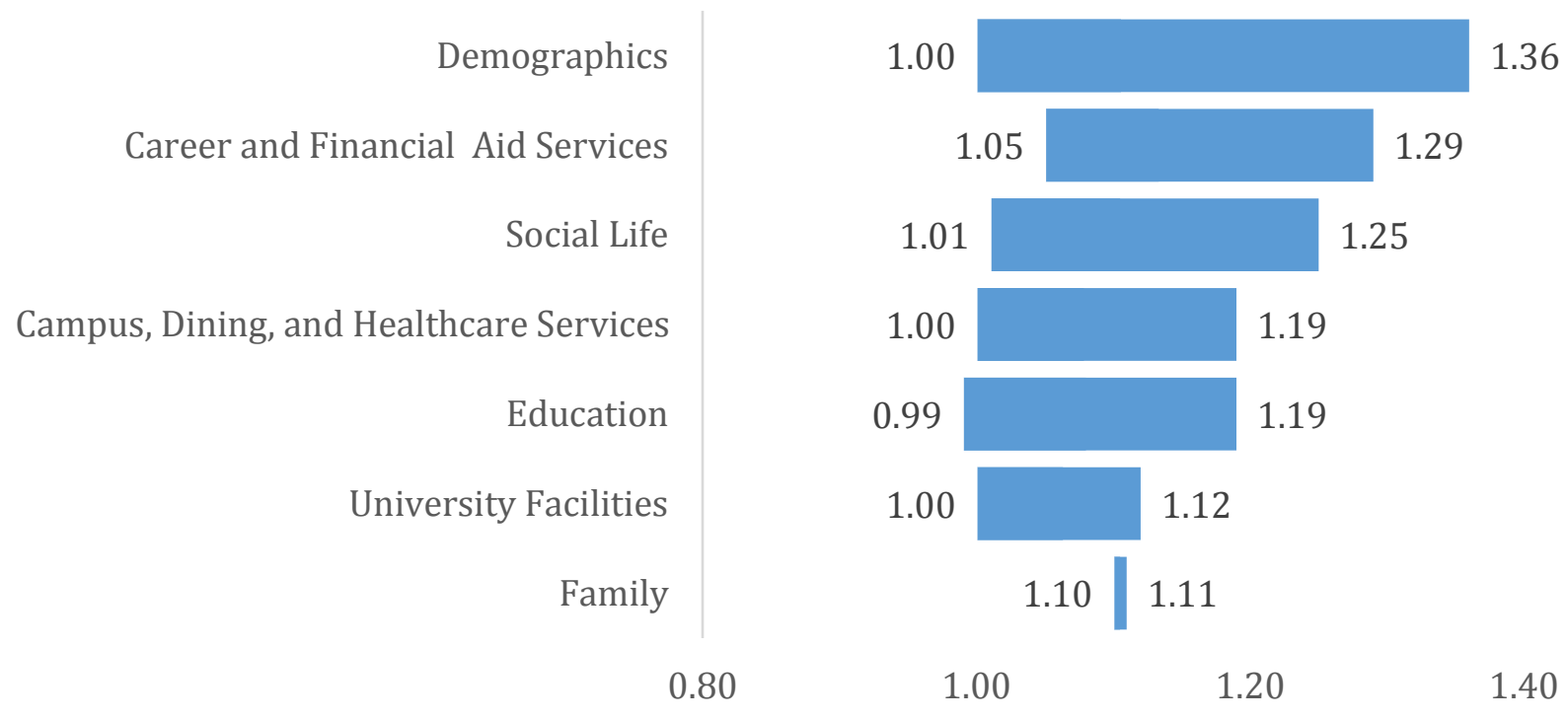

Figure 8. Overall Sensitivity Results

\section{Conclusions and Future Work}

In this paper, the determinants of student happiness is studied with an integrated analytical framework that consists of survey, data collection, linear and nonlinear analytical modeling and analysis. A small non-profit private university was selected to implement the proposed analytical framework. During the survey design, thirty-two categories (determinants of happiness) were identified as input variables and the output variable was identified as the perceived overall happiness. After survey administration, the results were recorded into a dataset, which was followed up with data cleaning and data preparation steps. In the further stage of the project, ANN model was developed to understand the relationship between the factors that affect student happiness (inputs) and the response variable, overall happiness. In addition, an MLR model was developed to establish a benchmark in evaluating the performance of the ANN approach.

The initial descriptive and graphical analysis of survey results indicated that parking, career services, especially campus jobs and financial aid are critical determinants, which lead to the highest levels of dissatisfaction. On the other hand, university reputation, facilities, professors, and classmates, and family relationship categories were identified with the highest level of satisfaction. Later in the second phase, the satisfaction levels in all of the input categories (determinants) were further studied to understand their potential impact on the overall happiness. 
Table 8. Detailed Sensitivity Results

\begin{tabular}{|c|c|c|c|}
\hline Main Category & $\begin{array}{c}\text { Avg. } \\
\text { Sensitivity } \\
\end{array}$ & Sub-Category & $\begin{array}{r}\text { Sensitivit } \\
\mathbf{y} \\
\end{array}$ \\
\hline & & Gender & 1.23 \\
\hline & & Age & 1.00 \\
\hline & & Nationality & 1.36 \\
\hline & & Enrollment & 1.00 \\
\hline & & GPA & 1.06 \\
\hline & & Employment status & 1.05 \\
\hline & & Financial aid & 1.04 \\
\hline & & Academic reputation & 1.10 \\
\hline & & Classmates & 1.10 \\
\hline & & Educational workload & 0.99 \\
\hline & & Professors & 1.02 \\
\hline & & Lecture quality & 1.19 \\
\hline & & University technology & 1.12 \\
\hline & & Main campus library & 1.07 \\
\hline & & Places for group working & 1.00 \\
\hline & & Career center & 1.29 \\
\hline & & Campus jobs & 1.06 \\
\hline & & Financial aid services & 1.05 \\
\hline & & Parking availability & 1.11 \\
\hline & & Campus Safety & 1.19 \\
\hline & & Dining: Food taste & 1.09 \\
\hline & & Dining: Food variety & 1.01 \\
\hline & & Overall dining services & 1.00 \\
\hline & & Health services & 1.08 \\
\hline & & Health insurance & 1.05 \\
\hline & & Campus cleanness & 1.10 \\
\hline & & Intercultural events & 1.01 \\
\hline & & Sports activities & 1.25 \\
\hline & & Sports facilities & 1.02 \\
\hline & & Outdoor activities & 1.14 \\
\hline & & Family relationship & 1.10 \\
\hline & & $\begin{array}{l}\text { Financial support from } \\
\text { family }\end{array}$ & 1.11 \\
\hline
\end{tabular}


In the second stage, analytical assessment results indicated that the percent variability in student happiness response variable explained by the input variables was 53\% with MLR and $71 \%$ with ANN. Due to its lower standard error of estimate (SEE: 0.016) and higher Rsquare (71\%), ANN approach was selected and used as the main approach for the analytical assessment. One thousand ANN models were developed and top 5 neural networks were picked based on error rate and r-square values, and analyzed in detail. The best ANN network consisted of 8 hidden layers with exponential activation functions and logistic activation function with the output (due to being a categorical output). ANN outperformed MLR due to nonlinear characteristics of the data and having categorical input and output variables. Finally, sensitivity analysis was conducted, which showed that all factor areas tend to have similar sensitivity relationship with the output, indicating that all areas of policy making needs to be addressed adequately and effectively to raise the student happiness.

This paper contributed to the literature significantly in four ways. First of all, it was found that focusing on factors such as family support, family relationships, and critical demographics in addition to school or education related categories provided more insights about the happiness determinants. Secondly, this study used the largest pool of indicators (32) to study and investigate the determinants of happiness in higher education. Thirdly, the proposed analytical approach critically helped identifying nonlinear relationships between determinants and overall happiness, which was also supported higher r-square and lower SEE. Fourthly, the global sensitivity analysis also provided meaningful insights, which was not possible with the classical regression-based approaches. Use of artificial intelligence, especially neural networks, could be of importance and beneficial for problems where categorical and binary variables exist, nonlinear relationships cannot be captured by parametric methods.

Further investigation of current work, could typically include other nonparametric methods such as decision trees, or alternative assessment approaches such as Exploratory Factor Analysis (EFA) to compare the performance of current models and increase the accuracy of predicting happiness. In addition, other close-by institutions could be also studied in parallel to make benchmarking among different institutions, and to build stronger models with larger training datasets. s more insights for future work. Lastly, the current research could be advanced by integrating subject expert weightings on the input variables prior to modeling, which could derive interesting results to compare with the current findings.

\section{Appendix}

IRB certification of the research project was obtained from the IRB Committee of the corresponding author's institution prior to survey design and data collection. Additionally, the research team members obtained IRB certification prior to the start of research project. 


\section{References}

Abecia, D. R., Samong, M., Abella, L., Baldomero, F., Tamayo, A., \& Gabronino, R. (2014). Measuring happiness of university students. In Social Sciences Research Network (Vol. 2, pp. 43-48). Retrieved from http://ssrn.com/abstract=2433950

Appleton-Knapp, S. L., \& Krentler, K. A. (2006). Measuring Student Expectations and Their Effects on Satisfaction: The Importance of Managing Student Expectations. Journal of Marketing Education, 28(3), 254-264. https://doi.org/10.1177/0273475306293359

Athiyaman, A. (2001). A longitudinal analysis of the impact of student satisfaction on attitude toward the university.pdf. Allied Academies International Conference.

Begg, R., Kamruzzaman, J., \& Sarker, R. (2006). Neural Networks in Healthcare : Potential and Challenges. Victoria. https://doi.org/10.4018/978-1-59140-848-2

Brodsky, E., \& Darkhovsky, B. S. (2000). Non-Parametric Statistical Diagnosis: Problems and Methods. Springer.

Burbuagh, B., Drape, T., \& Westfall-Rudd, D. (2014). A Descriptive Account of Factors Affecting Student Satisfaction in an Online Master's Degree in Agriculture and Life Sciences. NACTA, 58, 341-348. Retrieved from http://search.proquest.com/openview/318f42572868906ef38f8d46779bad86/1?pqorigsite $=$ gscholar

Chen, H.-C., Farmer, S., Barber, L., \& Wayman, M. (2012). Development and Psychometric Testing of the Nursing Student Satisfaction Scale. Nursing Education Perspectives, 33(6), 369-373. https://doi.org/10.1177/1054773812440810

Çodur, M. Y., \& Tortum, A. (2015). An Artificial Neural Network Model for Highway Accident Prediction: A Case Study of Erzurum, Turkey. PROMET - Traffic\&Transportation, 27(3). https://doi.org/10.7307/ptt.v27i3.1551

DeShields, O. W., Kara, A., \& Kaynak, E. (2005). Determinants of business student satisfaction and retention in higher education: applying Herzberg's two-factor theory. International Journal of Educational Management, 19(2), 128-139. https://doi.org/10.1108/09513540510582426

Diener, E., Sandvik, E., Seidlitz, L., \& Diener, M. (1993). The relationship between income and subjective well-being: Relative or absolute? Social Indicators Research, 28(3), 195-223. https://doi.org/10.1007/BF01079018

Egilmez, G., Celikbilek, C., Altun, M., \& Süer, G. A. (2016). Cell loading and shipment optimisation in a cellular manufacturing system: An integrated genetic algorithms and neural network approach. International Journal of Industrial and Systems Engineering, 24(3). https://doi.org/10.1504/IJISE.2016.079822

Egilmez, G., \& McAvoy, D. (2017). Predicting nationwide road fatalities in the US: a neural 
network approach. International Journal of Metaheuristics, (Forthcoming). https://doi.org/10.1504/IJMHEUR.2017.10006776

Graham, C., \& Felton, A. (2006). Inequality and happiness: Insights from Latin America. Journal of Economic Inequality, 4(1), 107-122. https://doi.org/10.1007/s10888-0059009-1

Gruber, T., Fuß, S., Voss, R., \& Gläser-Zikuda, M. (2010). Examining student satisfaction with higher education services. International Journal of Public Sector Management, 23(2), 105-123. https://doi.org/10.1108/09513551011022474

Guolla, M. (1999). Assessing the Teaching Quality to Student Satisfaction Relationship: Applied Customer Satisfaction Research in the Classroom. Journal of Marketing Theory and Practice, 7(3), 87-97. https://doi.org/10.1080/10696679.1999.11501843

Hale, L. S., Mirakian, E. A., \& Day, D. B. (2009). Online vs. classroom instruction: Student satisfaction and learning outcomes in an undergraduate allied health pharmacology course. Journal of Allied Health, 38(2), 36-43.

Herzog, S. (2009). Estimating Student Retention and Degree-Completion Time: Decision Trees and Neural Networks Vis-à-Vis Regression. New Directions for Institutional Research, 2006(131), 17-31. https://doi.org/10.1002/ir

Howell, G. F., \& Buck, J. M. (2012). The Adult Student and Course Satisfaction: What Matters Most? Innovative Higher Education, 37(3), 215-226. https://doi.org/10.1007/s10755011-9201-0

Ismail, N., Hassan, F. H., \& Sheriff, N. M. (2011). Student Satisfaction Formation : Linkage Between Information Satisfaction and College Choice Satisfaction. In European Conference on Research Methodology for Business and Management Studies.

Kar, A. K., \& Singh, P. (2012). A model for bundling mobile value added services using neural networks. International Journal of Applied Decision Sciences, 5(1), 47. https://doi.org/10.1504/IJADS.2012.044946

Kardan, A., Sadeghi, H., Ghidary, S. S., \& Sani, M. R. F. (2013). Prediction of students course selection in online higher education institutes using NN. Computers \& Education, 65, 111.

Kärnä, S., \& Julin, P. (2015). A framework for measuring student and staff satisfaction with university campus facilities. Quality Assurance in Education, 23(1), 47-66. https://doi.org/10.1108/QAE-10-2013-0041

Kaytez, F., Taplamacioglu, M. C., Cam, E., \& Hardalac, F. (2015). Forecasting electricity consumption: A comparison of regression analysis, neural networks and least squares support vector machines. International Journal of Electrical Power and Energy Systems, 67, 431-438. https://doi.org/10.1016/j.ijepes.2014.12.036 
Kirmizi, O. (2015). the Influence of Learner Readiness on Student Satisfaction and Academic Achievement in an Online Program At Higher Education. The Turkish Online Journal of Educational Technology, 14(1), 133-142.

Ko, M., Tiwari, A., \& Mehnen, J. (2010). A review of soft computing applications in supply chain management. Applied Soft Computing, 10(3), 661-674. https://doi.org/http://dx.doi.org/10.1016/j.asoc.2009.09.004

Layard, R. (2005). Happiness: Lessons from a new science. New York: Penguin Publishing Group.

Lu, L., \& Argyle, M. (1994). Leisure satisfaction and happiness as a function of leisure activity. The Kaohsiung Journal of Medical Sciences, 10(2), 89-96.

Maceli, K. M., Fogliasso, C. E., \& Baack, D. (2011). DIFFERENCES OF STUDENTS ' SATISFACTION WITH COLLEGE PROFESSORS : THE IMPACT OF STUDENT GENDER ON. Academy of Educational Leadership Journal, 15(4), 35-46.

Maleki, M. R., Mousavi, S. ., \& Amiri, A. (2015). A new neural network-based control scheme for fault detection and fault diagnosis in fuzzy multivariate multinomial data. International Journal of Applied Decision Sciences, 8(2).

Martin, P. (2014). Making happy people: The nature of happiness and its origins in childhood. HarperCollins UK.

Misanew, A., \& Tadesse, M. (2014). Determinants of Student and Staff Satisfaction with Services at Dilla University, Ethiopia: Application of Single and Multilevel Logistic Regression Analyses. Social Indicators Research, 1-17. https://doi.org/10.1007/s11205-013-0561-y

Mousavizadeh, R., \& Khalili-Damghani, K. (2017). Cooperative mechanism based on data envelopment analysis and artificial neural network to measure efficiency: Case study of Iranian ports. International Journal of Applied Decision Sciences, 10(1), 52-68. https://doi.org/10.1504/IJADS.2017.081790

Naik, B., \& Ragothaman, S. (2004). Using Neural Networks to Predict MBA Student Success. College Student Journal, 38(1), 143-150. https://doi.org/10.1037/t04058-000

Nyhus, O. H. (2015). Does student satisfaction with school facilities affect exam results? An empirical investigation. https://doi.org/10.1108/F-09-2014-0076

Oxford University Press. (2018). English Oxford Living Dictionary. Retrieved from https://en.oxforddictionaries.com/definition/satisfaction

Parkins, J. R., Stedman, R. C., \& Varghese, J. (2016). Social Indicators Research. JSTOR, 56(1), 43-72.

Roszkowski, M. J., \& Ricci, R. (2004). Measurement of Importance in a Student Satisfaction Questionnaire: Comparison of the Direct and Indirect Methods for Establishing 
Attribute Importance. Journal of College Student Retention Research Theory and Practice, 6(3), 251. https://doi.org/10.2190/GEPA-2RNR-GK7P-5JMC

Şahin, M., Kaya, Y., \& Uyar, M. (2013). Comparison of ANN and MLR models for estimating solar radiation in Turkey using NOAA/AVHRR data. Advances in Space Research, 51(5), 891-904. https://doi.org/10.1016/j.asr.2012.10.010

Shi, W., Drzymalski, J., \& Guo, J. (2014). Measuring College Student Satisfaction : Analyzing Interactions among Student Attributes Department of Industrial Engineering and Engineering Management, 2075-2085.

Shokrzadeh, S., Jafari Jozani, M., \& Bibeau, E. (2014). Wind turbine power curve modeling using advanced parametric and nonparametric methods. IEEE Transactions on Sustainable Energy, 5(4), 1262-1269. https://doi.org/10.1109/TSTE.2014.2345059

Statistica. (2017). Sensitivity Analysis. Retrieved from http://documentation.statsoft.com/STATISTICAHelp.aspx?path=glossary/GlossaryTw o/S/SensitivityAnalysis

Stephanie, F., \& M.Macleod, D. (2015). Determinants of Happiness in Undergraduate University Students. College Student Journal, 49(3), 452-460. Retrieved from http://search.ebscohost.com/login.aspx?direct=true \&db=pbh\&AN=109506018\&site= eds-live

Sun, J., \& Chang, T. (2016). Prediction of rural residents' tourism demand based on back propagation neural network. International Journal of Applied Decision Sciences, 9(3), 320. https://doi.org/10.1504/IJADS.2016.081095

Tatari, O., \& Kucukvar, M. (2011). Cost premium prediction of certified green buildings: A neural network approach. Building and Environment, 46(5), 1081-1086. https://doi.org/10.1016/j.buildenv.2010.11.009

Tatari, O., \& Kucukvar, M. (2011). Cost premium prediction of certified green buildings: A neural network approach. Building and Environment, 46(5), 1081-1086. Retrieved from http://dx.doi.org/10.1016/j.buildenv.2010.11.009

Turkyilmaz, A., Temizer, L., \& Oztekin, A. (2016). A causal analytic approach to student satisfaction index modeling. Annals of Operations Research, 1-21. https://doi.org/10.1007/s10479-016-2245-x

Türkyılmaz, A., \& Özkan, C. (2007). Development of a customer satisfaction index model. Industrial Management \& Data Systems, 107(5), 672-687. https://doi.org/10.1108/02635570710750426

Wang, S. (2016). Stock price prediction based on chaotic hybrid particle swarm optimisationRBF neural network. International Journal of Applied Decision Sciences, 10(2).

Zarei, S. (2013). INVESTIGATING THE FACTORS HAVING INFLUENCE ON THE STUDENT 
â€TM S HAPPINESS : A SURVEY BETWEEN STUDENTS OF SECONDARY SCHOOLS OF, (4).

Zhang, Y., Shang, W., \& Wu, Y. (2009). Research on sustainable development based on neural network. In 2009 Chinese Control and Decision Conference (pp. 3273-3276). IEEE. https://doi.org/10.1109/CCDC.2009.5192476 